\title{
Trace element discrimination of garnet from diamondiferous kimberlites and lamproites.
}

\author{
Pearson, N.J. ${ }^{1}$, Griffin, W.L. ${ }^{1,2}$, Kaminsky, F.V. ${ }^{3}$,van Achterbergh, E. ${ }^{1}$ and O'Reilly, S.Y. ${ }^{1}$
}

1. GEMOC National Key Centre, School of Earth Sciences, Macquarie University, NSW 2109, Australia

2. CSIRO Exploration and Mining, PO Box 126, North Ryde, NSW 2113, Australia

3. KM Diamond Exploration Ltd, 815 Evelyn Drive, West Vancouver, BC V7T 1J1, Canada

The major element composition of chrome-pyrope garnets has been used extensively to establish criteria for target evaluation in diamond exploration. Trace element data provide additional information that can be used to quantify parameters indicative of the diamond grade of a kimberlite or lamproitic host rock (Griffin and Ryan, 1995). This method originally was based on the small group of elements obtained using the proton microprobe. The current study using laser ablation ICP-MS was undertaken to establish the characteristics of a larger group of trace elements in garnet concentrates from diamondiferous and barren kimberlites. To define the trace element features of garnet most likely to coexist with diamond, a number of syngenetic garnet inclusions in diamond were also included in the study.

In-situ quantitative analysis by Laser Ablation Microprobe (LAM) ICP-MS has rapidly developed into one of the most powerful analytical techniques in geochemistry, capable of producing high precision determinations of trace elements at sub-ppm detection limits. The laser ablation system at Macquarie University was designed and installed by Drs Simon Jackson and Henry Longerich of Memorial University, Newfoundland. This system includes a Continuum Surelite I-20 Q-switched Nd-YAG laser with a fundamental wavelength of $1064 \mathrm{~nm}$ (IR) and frequency doubling crystals which produce $532 \mathrm{~nm}$ (visible) and $266 \mathrm{~nm}$ (UV) wavelengths. Operation in the UV wavelength produces enhanced ablation yields for materials with low abundances of transition elements. Typical operating conditions for the quantitative analysis of the garnets in this study involved energies of 0.5 to $2 \mathrm{~mJ}$ per pulse at a repetition rate of $4 \mathrm{~Hz}$. Under these conditions the pit size produced is between 30 to $60 \mu \mathrm{m}$ in diameter and the drill rate is approximately $0.5 \mu \mathrm{m} / \mathrm{sec}$. Ablation times of up to 120 secs were achieved in $0.5 \mathrm{~mm}$. A full description of the LAM instrumentaion and ICP-MS operating conditions is given in Norman et al. (1996). A suite of 20 to 30 minor and trace elements was determined in each analysis and $\mathrm{Ca}$ was used as the internal standard in the quantification procedure. Detection limits for all elements in this study are typically in the range $100 \mathrm{ppb}$ to $1 \mathrm{ppm}$, although actual values for individual analyses will depend on ablation time, which is largely a function of grain size, and on the internal standard concentration.

Sub-calcic and lherzolitic Cr-pyropes in concentrates from several different cratons were analysed: Kaapvaal craton (Newlands, Leicester, Uintjiesberg, Liqhobong); Siberian craton (Sytkanskaya); Slave craton (A-10). The garnet inclusions in diamond are also derived from kimberlites of equal geographical diversity: Yakutia; Venezuela; Ghana; Canada. Our diamond inclusion data are supplemented by ion probe analyses of diamond inclusion garnets from southern Africa and Siberia (Yakutia) from Shimizu and Richardson (1987 and Shimizu and Sobolev (1995). Shimizu and Sobolev did not report Sc data, so we have assumed a value of $130 \mathrm{ppm}$, equal to the average of the other diamond inclusion peridotite group garnets.

The relationships between elements such as $\mathrm{Zr}$, Y and Ti were used by Griffin and Ryan (1995) to identify the chemical signatures of different types of mantle processes. Plots of these elements in the concentrate and diamond inclusion garnets in this study confirm previous observations that garnet inclusions in diamonds have depleted trace element patterns (Fig. 1; Griffin et al., 1992; Griffin et al., 1993). The majority of diamond inclusion garnets have $\mathrm{Zr}$ contents $<20 \mathrm{ppm}, \mathrm{Y}<8 \mathrm{ppm}$ and Ti from 10 to $2000 \mathrm{ppm}$. A significant proportion of the garnets from the more diamondiferous pipes (Liqhobong, Newlands; Sytkanskaya) fall within the field defined by the diamond inclusion garnets. Conversely, garnets from the barren kimberlites (Uintjiesberg) plot outside the field of diamond inclusions on these diagrams (Fig. 2). 


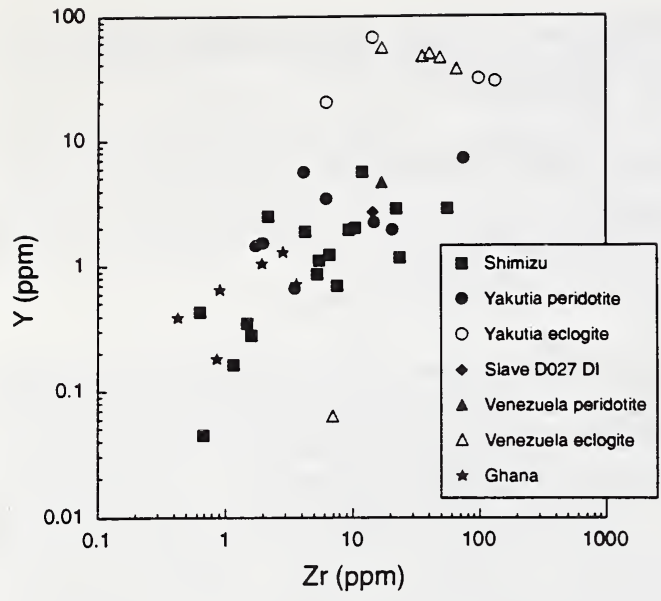

Fig 1. $\mathrm{Zr}$ vs $\mathrm{Y}(\mathrm{ppm})$ for diamond inclusion garnets.

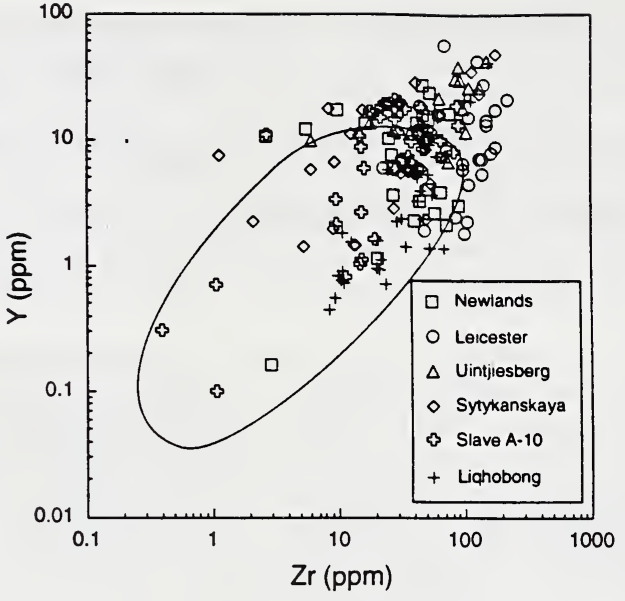

Fig 2. $\mathrm{Zr}$ vs $\mathrm{Y}$ (ppm) for Cr-pyrope garnet in concentrate from kimberlite pipes. The field defined by peridotitic garnet inclusions in diamond is drawn from Fig. 1 .
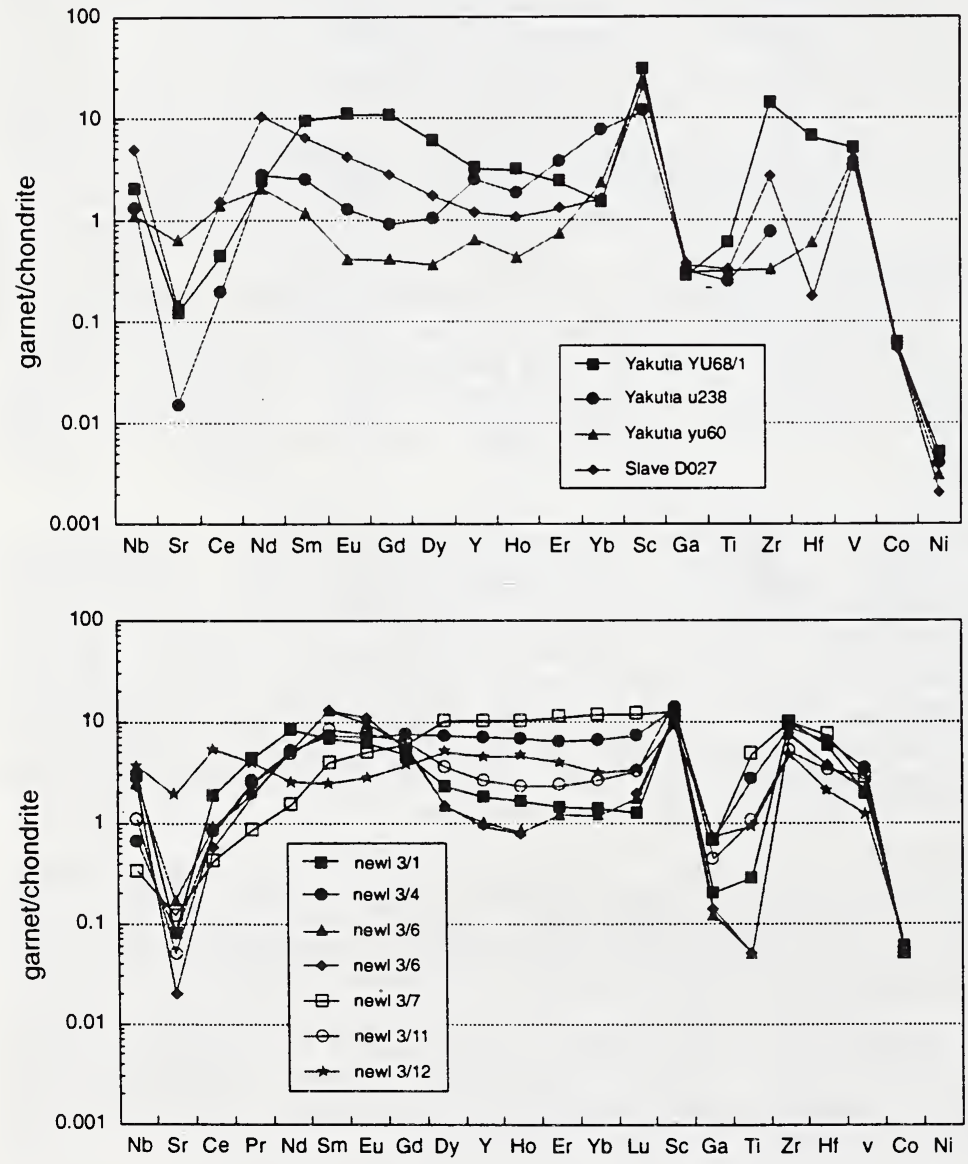

Fig. 3 Chondrite normalised plot of selected peridotitic garnet inclusions in diamond from Yakutia and Slave D027.

Fig.4 Chondrite normalised plot of selected peridotitic garnet in concentrate from Newlands kimberlite. 
The depleted nature of the diamond inclusion garnets is apparent in chondrite normalised plots (Fig. 3). HREE in many of the garnets, including both harzburgitic and lherzolitic ones, are strongly depleted in HREE and enriched in MREE giving rise to sinuous REE patterns, with convex up LREE to MREE and concave up MREE to HREE. The point of inflection is at $\mathrm{Sm} / \mathrm{Eu}$ in the most depleted garnets and shifts to Gd/Dy as the concentration of HREE increases in less depleted garnets. The distinctive REE pattern for the diamond inclusion garnets is also developed in some sub-calcic garnets in the concentrates, particularly those with trace element signatures indicating ultradepletion. Lherzolitic garnets have more typical convex-up patterns, with nearly flat REE patterns from Dy to Lu (Fig. 4).

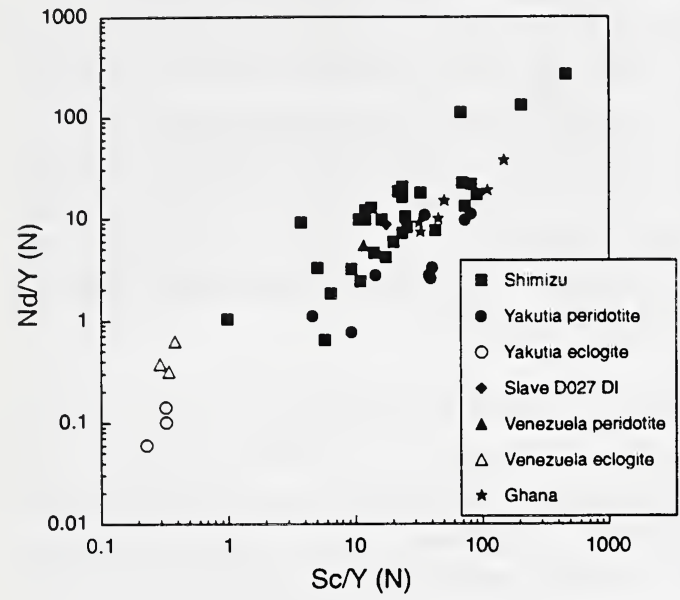

Fig 5. $\mathrm{Sc} / \mathrm{Y}(\mathrm{N})$ vs $\mathrm{Nd} / \mathrm{Y}(\mathrm{N}))$ for diamond inclusion garnets.

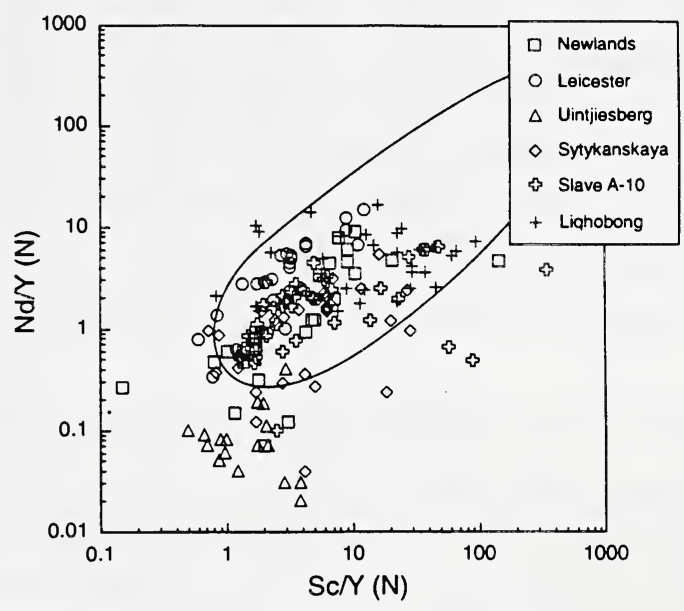

Fig 6. $\mathrm{Sc} / \mathrm{Y}(\mathrm{N})$ vs $\mathrm{Nd} / \mathrm{Y}(\mathrm{N}))$ for $\mathrm{Cr}$-pyrope garnet in concentrate from kimberlite pipes. The field defined by peridotitic garnet inclusions in diamond is drawn from Fig. 5.

The significance of the range in the shapes of these patterns is evident in the plots of $N d / Y(N)$ versus $\mathrm{Sc} / \mathrm{Y}(\mathrm{N})$ (Fig. 5 and Fig. 6). The $\mathrm{Nd} / \mathrm{Y}$ ratio clearly distinguishes garnets with the sinuous $\mathrm{REE}$ pattern $(\mathrm{Nd} / \mathrm{Y}>>1)$ from those with more typical LREE depleted patterns $(\mathrm{Nd} / \mathrm{Y}<<1)$. Sc contents in Cr-pyrope garnet fall within a very restricted range $(100-150 \mathrm{ppm})$ and because Sc appears to be preferentially accommodated into garnet during depletion, $\mathrm{Sc} / \mathrm{Y}$ provides a measure of the depletion of HREE. Values of $\mathrm{Sc} / \mathrm{Y} \gg>1$ are indicative of the depleted compositions, whereas $\mathrm{Sc} / \mathrm{Y} \sim 1$ are obtained from undepleted lherzolitic garnets. The quadrant defined by $\mathrm{Nd} / \mathrm{Y}>1$ and $\mathrm{Sc} / \mathrm{Y}>1$ contains all of the diamond inclusion garnets and a significant number of garnets from the diamondiferous pipes. This plot and a plot of $\mathrm{Zr} / \mathrm{Y}(\mathrm{N})$ versus $\mathrm{Sc} / \mathrm{Y}(\mathrm{N})$ (not shown here) provide examples of the simple discrimination tests using the expanded trace element suite to estimate the diamond potential of a pipe. Diamondiferous pipes such as Sytykanskaya, Liqhobong, Newlands and Slave have up to $70 \%$ of the Cr-pyrope garnets plotting in the field defined by the diamond inclusions. In the lowgrade Leicester pipe the proportion of concentrate diamonds in the diamond inclusion field is $<50 \%$, and in the barren Uintjiesberg pipe the proportion is nil.

\section{References}

Griffin, W.L. and Ryan, C.G., 1995. J. Geochem. Explor., 53, 311-337.

Griffin, W.L., Gurney, J.J. and Ryan, C.G., 1992. Contrib. Mineral. Petrol., 110, 1-15.

Griffin, W.L., Sobolev, N.V., Ryan, C.G., Pokhilenko, N.P., Win, T.T. and Yefimov, Y., 1993. Lithos, 29, $235-256$

Norman, M.D., Pearson, N.J., Sharma, A. and Griffin, W.L., 1996. Geostandards Newsletter, 20, $247-261$.

Shimizu, N. and Richardson, S., 1987. Geochim. Cosmochim. Acta, 51, 755-758.

Shimizu, N. and Sobolev, N.V., 1995. Nature, 375, 394-397. 